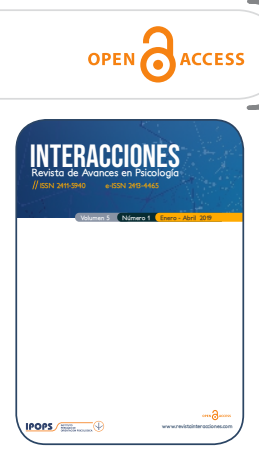

\title{
EDITORIAL
}

\section{¿Temor de compartir los datos?: La necesidad de una ciencia más abierta}

\author{
Fear of sharing the data?: The need for a more open science
}

\author{
David Villarreal-Zegarra ${ }^{1}$ (D) , Milagros Cabrera-Alva ${ }^{1}$ iD y David Villarreal-Huertas ${ }^{1 *}$ \\ ${ }^{1}$ Instituto Peruano de Orientación Psicológica, Lima, Perú. \\ "Correspondencia: David Villarreal Huertas; Jr. Manuel Corpancho, 208, Lima, Perú. Correo: revistainteracciones@ipops.pe \\ Recibido: 10 de diciembre de 2018; Revisado: 21 de diciembre de 2018; Aceptado: 10 de diciembre de 2018; Publicado Online: 01 de enero de 2019. \\ CITARLO COMO: \\ Villarreal-Zegarra, D., Cabrera-Alva, M., Villarreal-Huertas, D. (2019). ¿Temor de compartir los datos?: La necesidad de una ciencia más \\ abierta. Interacciones, 5(1), 3-5. doi: 10.24016/2019.v5n1.169
}

La obtención de data primaria es parte fundamental del proceso de investigación, por lo que instituciones e investigadores invierten gran cantidad de recursos que garanticen su calidad y rigurosidad metodológica. Sin embargo; la falta de financiamiento, recursos e incentivos repercuten en la disminución de la productividad científica. De modo que se podrían desestimar ideas relevantes de investigación o se opten por métodos con menor rigor metodológico (ToroHuamanchumo, Arce-Villalobos, Gonzales-Martínez, Melgarejo-Castillo, \& Taype-Rondán, 2017). Ante esta dificultad, una forma de aprovechar al máximo los recursos limitados y propiciar el desarrollo de la investigación científica, es publicar los datos en acceso abierto. En ese sentido, el movimiento Open Data posibilita el uso libre y sin restricciones de las bases de datos; permitiendo que los investigadores puedan producir nuevas investigaciones. Esto permite que los datos puedan ser utilizados, reutilizados y redistribuidos libremente por cualquier persona con el único requisito de brindar atribución al autor (Molloy, 2011).

En 2014 el equipo de SciELO estimó que aproximadamente el $80 \%$ de los datos no estarán disponibles pasado los 20 años de su publicación debido a la baja probabilidad de ponerse en contacto con el autor (Nassi-Calò, 2014). Esto podría ser explicado por la percepción de los investigadores respecto a liberar sus datos. Un estudio en investigadores y profesionales de diversas áreas del conocimiento identificó diferentes barreras para publicar artículos en open data (Schmidt, Gemeinholzer, \& Treloar, 2016; Tenopir et al., 2011). Siendo uno de los principales motivos la necesidad de publicar los resultados de forma rápida, ya que normalizar las bases de datos puede llegar a ser costoso y lleva tiempo. Otras barreras consideradas fueron las restricciones legales de las licencias y sus procedimientos, temor a no ser reconocidos como los autores de la data primaria (no citen el trabajo original), la posibilidad de que la base de datos se utilice de forma inadecuada y la falta de incentivos por parte de los financiadores para que los científicos publiquen sus estudios con datos abiertos (Schmidt et al., 2016).

Brindar acceso libre a las bases de datos, códigos de análisis y demás información útil, conlleva abundantes beneficios tanto para el autor como para la comunidad científica (Roche et al., 2014). En caso de los autores, incrementa la visibilidad, difusión e impacto de sus investigaciones; lo cual influye positivamente en el número de citaciones recibidas (Piwowar \& Vision, 2013; Tenopir et al., 2011). Asimismo, la exposición de los artículos publicados con open data gene- 
ran que los autores sean más rigurosos y responsables en el desarrollo de su investigación (Piwowar, Day, \& Fridsma, 2007). En caso de la comunidad científica, contribuye a la transparencia de la información y evita el fraude en ciencia. Así también incrementa el debate científico, permite realizar análisis adicionales, combinar estudios con datos similares y mejorar la replicabilidad de los resultados (Kratz \& Strasser, 2015).

La fundación Open Knowledge International (s. f.) sugiere cuatro pasos flexibles a seguir para publicar datos en acceso abierto. El primer paso, elegir el conjunto de datos que se desea liberar (base de datos, scripts de R o STATA, instrumentos de evaluación, vídeos, etc.). Segundo, seleccionar el tipo de licencia de uso según se ajusten a los intereses del autor; se puede utilizar las licencias Creative Commons, Open Data Commons u otras. Se recomienda conocer los derechos de propiedad intelectual de cada una de las licencias. En la figura 1 se explica de forma breve cuales son los tipos de licencia Creative Commons más usuales y cual es tipo de uso que permiten. Cabe señalar que el equipo editorial de Interacciones sugiere el uso de las licencias CC-BY 4.0. Tercero, normalizar los datos o crear una manual de usuario que permita identificar las variables de estudio, las opciones de respuestas, la codificación de los datos perdidos, entre otro tipo de información relevante. Cuarto y último, subir los datos en una plataforma que permita su almacenamiento permanente, para esto se puede utilizar un repositorio institucional (e.g. DSpace), el sistema de la revista (e.g. Open Journal Systems), o mediante una plataforma gratuita para bases de datos (e.g. Open Science Framework; Figshare) o para código (e.g. Github). En caso se desee conocer más acerca de las prácticas y tendencias emergente de la gestión de datos en investigación, se invita al lector a revisar la publicación del Council on Library and Information Resources (2013).

Este editorial tiene el objetivo de motivar a los diferentes actores de la comunidad científica de la región a compartir los datos derivados del proceso de investigación, en especial a los investigadores, representante de instituciones financiadoras y editores de revistas científicas. Lo que posibilitaría una ciencia más abierta, transparente y replicable. Invitamos a las instituciones financiadoras a priorizar o condicionar el acceso al financiamiento a aquellos proyectos que contemplen liberar sus datos en acceso abierto. Asimismo, invitamos a los editores de revistas científicas a promover la publicación de artículos que brinden acceso abierto a sus datos; ya sea volviéndolo un requisito para su evaluación o priorizando aquellos artículos que liberen sus datos. Esta práctica es cada vez en más común en diferentes revistas de alto impacto (Vasilevsky, Minnier, Haendel, \& Champieux, 2017). Es por ello que Interacciones presenta su política de acceso abierto a los datos, dando prioridad en la revisión y publicación a aquellos artículos que brinden acceso libre a sus datos.

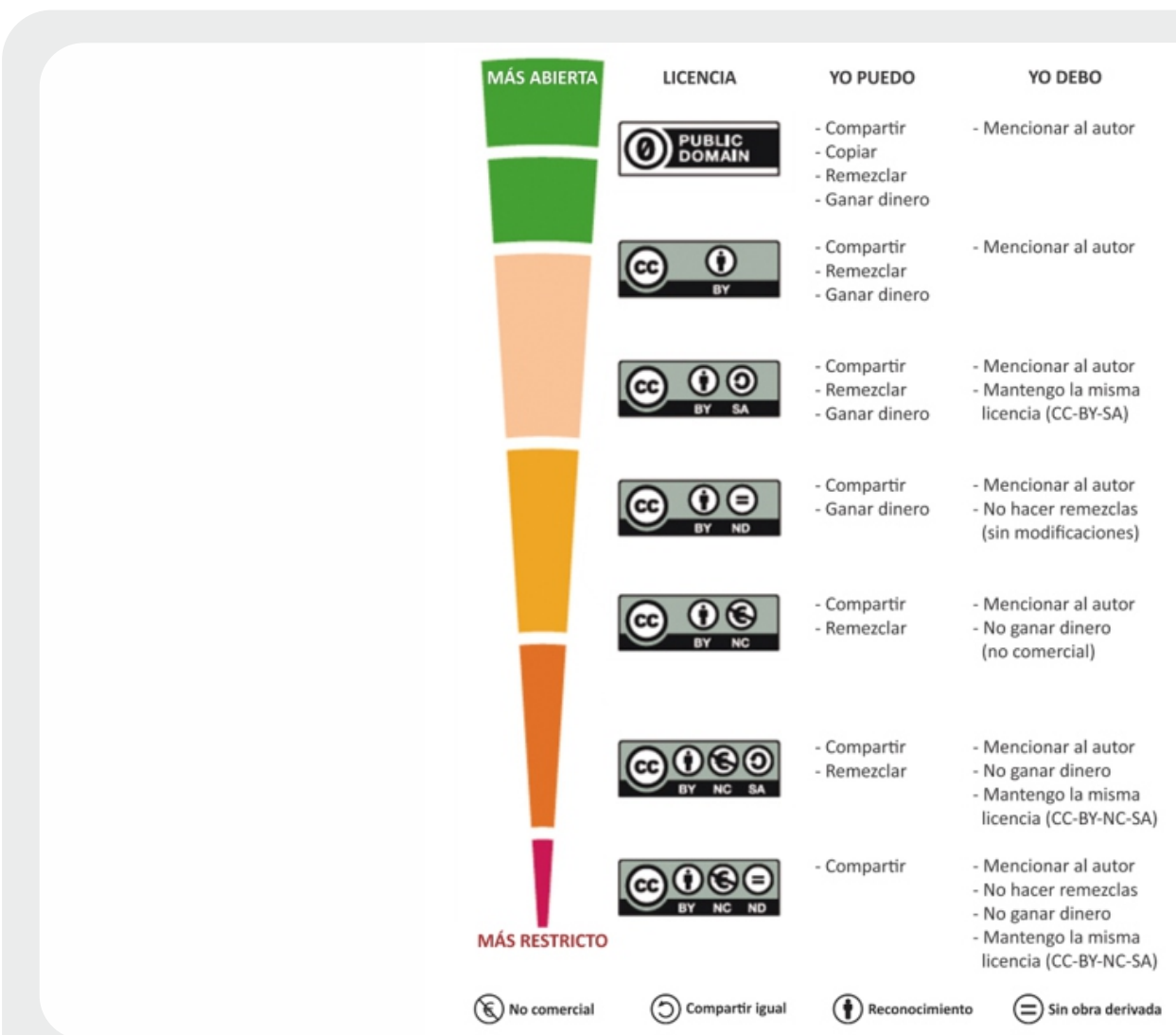

Figura 1. Tipos de licencias Creative Commons versión 4.0. Adaptado de http://www.blogcreacultura.com/combinaciones-creative-commons/ 


\section{CONFLICTO DE INTERÉS}

Los autores refieren no tener conflictos de interés.

\section{FINANCIAMIENTO}

El presente estudio fue autofinanciado.

\section{AGRADECIMIENTOS}

Los autores agradecen a Anthony Copez-Lonzoy, Victoria Yance y Brian Peña por revisar el manuscrito.

\section{REFERENCIAS}

Council on Library and Information Resources. (2013). Research Data Management: Principles, Practices, and Prospects. Washington: CLIR Publication.

Kratz, J. E., \& Strasser, C. (2015). Researcher Perspectives on Publication and Peer Review of Data. PLoS One, 10(2), e0117619. doi:10.1371/journal.pone.0117619

Molloy, J. C. (2011). The Open Knowledge Foundation: Open Data Means Better Science. PLOS Biology, 9(12), e 1001195. doi:10.1371/journal.pbio.1001195

Nassi-Calò, L. (2014). El Movimiento Open Data se consolida internacionalmente. Retrieved from https://blog.scielo.org/es/2014/07/14/elmovimiento-open-data-se-consolida-internacionalmente/

Open Knowledge International. (s. f.). How to Open Data. Retrieved from https://okfn.org/opendata/how-to-open-data/

Piwowar, H. A., Day, R. S., \& Fridsma, D. B. (2007). Sharing Detailed Research Data Is Associated with Increased Citation Rate. PLoS One, 2(3), e308. doi:10.1371/journal.pone.0000308

Piwowar, H. A., \& Vision, T. J. (2013). Data reuse and the open data citation advantage. PeerJ, 1, e175. doi:10.7717/peerj.175

Roche, D. G., Lanfear, R., Binning, S. A., Haff, T. M., Schwanz, L. E., Cain, K. E., . .. Kruuk, L. E. B. (2014). Troubleshooting Public Data Archiving: Suggestions to Increase Participation. PLOS Biology, 12(1), e1001779. doi:10.1371/journal.pbio.1001779

Schmidt, B., Gemeinholzer, B., \& Treloar, A. (2016). Open Data in Global Environmental Research: The Belmont Forum's Open Data Survey. PLoS One, 11(1), e0146695. doi:10.1371/journal.pone.0146695

Tenopir, C., Allard, S., Douglass, K., Aydinoglu, A. U., Wu, L., Read, E., . . . Frame, M. (2011). Data Sharing by Scientists: Practices and Perceptions. PLoS One, 6(6), e21101. doi:10.1371/journal.pone.0021101

Toro-Huamanchumo, C. J., Arce-Villalobos, L. R., Gonzales-Martínez, J., Melgarejo-Castillo, A., \& Taype-Rondán, Á. (2017). Financiamiento de la investigación en pregrado en las facultades de medicina peruanas. Gaceta Sanitaria, 31, 541-542.

Vasilevsky, N. A., Minnier, J., Haendel, M. A., \& Champieux, R. E. (2017). Reproducible and reusable research: are journal data sharing policies meeting the mark? PeerJ, 5, e3208. doi:10.7717/peerj.3208 